\title{
Social Meaning and the Possible Societal Responses to the Public Health Problem of Tuberculosis - Part 2
}

\author{
Vikas Bajpai ${ }^{1 *}$, Anoop Saraya ${ }^{2}$, Suman Bhasker ${ }^{3}$ \\ ${ }^{1}$ Centre for Social Medicine and Community Health, Jawaharlal Nehru University, New Delhi - 110067. \\ ${ }^{2}$ Department of Gastroenterology and Human Nutrition, All India Institute of Medical Sciences, New Delhi - 110029. \\ ${ }^{3}$ Department of Radiation Oncology, All India Institute of Medical Sciences, New Delhi.
}

\section{A B STRACT}

In part 1 we had discussed how social meaning of a disease is formed in general and the manner in which social meaning determines the societal response to disease. We have already deliberated in Part 1 upon the social meaning of tuberculosis. In this second part of the paper, we shall dwell at some length upon the societal response to tuberculosis at the level of the people, that of the scientific community and the administrative response at the level of the government and the bilateral and multilateral agencies. In this context the paper deals with the formulation of the National Tuberculosis Program (NTP) and the Revised National Tuberculosis Program (RNTCP) and relative merits of these programs in dealing with the epidemiology of tuberculosis in India.

Key words: Tuberculosis, RNTCP, NTP, Epidemiology, Technology

\section{INTRODUCTION}

We have seen in part 1 of the paper that societal response could be at three levels - of the people, of the scientific community (nationally and internationally) and of the governments moderated by the bilateral and multilateral agencies. These three types of responses are not mutually exclusive of eachother and are in a dynamic relationship that bears upon the epidemiologic dimensions of the public health problem of a disease.

However, if we go by the experience of health policy formation in the country since the transfer of power in 1947, we find that there is a great dilemma in this scheme of things. The dilemma can be understood as follows:

Suppose the government is the great ombudsman that has to make a cogent program that shall have the most favorable impact on the epidemiological dimensions of the disease; we also suppose that it is ably aided by the multilateral and the bilateral agencies without any malfeasance. Further, there can be two ways of approaching the problem - one that we begin with the latest scientific and technological tools

Address for correspondence:

Mobile: 9810275314.

E-mail: drvikasbajpai@gmail.com

DOI: 10.5530/ijmedph.3.2011.7 of dealing with the disease to impact on its epidemiological dimensions or, second, to begin with what is the prevalent social meaning of the disease and the health seeking behavior of the people; in other words, what are their felt needs with respect to their suffering caused by the disease, and accordingly choose the technology that will bring about a constructive change in the social meaning of the disease by suitably altering its epidemiology, and one that best suits the felt needs of the people.

There is a paradigm shift in the two approaches - while the former requires that the people be subordinated to the constraints placed by the technology; the latter requires giving primacy to the human suffering in a manner as to subordinate technology to the felt needs of the people to optimize the epidemiological impact of the disease control program and thereby changing the social meaning of the disease. The adopted paradigm determines the social orientation of a health program, how people's interest gets defined, what epidemiological tools and measurements we use to guide program implementation and the problems we study in the operations research regarding program implementation. All this is very well reflected in the approaches adopted in the formulation of NTP and RNTCP.

It need be borne in mind here that in the post World War II national and international health policy paradigms there has been a very strong propensity to "bring the power of modern biomedical science to bear on the great neglected 
diseases of mankind." "The conventional thinking leading to this propensity has been that the overall socio-economic development for improvement in morbidity and mortality due to diseases will take a long time in the context of the developing countries, especially as they lacked the resources to adequately fund such development and hence the expediency of deploying technology driven offensives through vertical health programs against the major public health problems. ${ }^{2}$ The dominance of this thinking in the multilateral and bilateral agencies ensured a considerable leverage in favor of technology as these were also the sources of financial and technical assistance for developing countries. ${ }^{1}$ Since it was the industrialized West where all the technology came from, the predominance of technology ensured perpetual dependence of developing countries on the West.

Most of the health programs that have been adopted in the country since the transfer of power in 1947, have conformed to the second paradigm shown in figure 1; beginning with the massive family planning program, the malaria control and eradication programs, the immunization program, the small pox eradication program, the safe motherhood and child survival program or the IMNCI (Integrated Management of Neonatal and Childhood Infections), RNTCP, the Janani Suraksha Yojna and the latest polio eradication program. The National Tuberculosis Program is the only notable exception in this series; being a home grown program based on painstaking and diligently conducted clinical, social science and operations research wherein the medical technology was quite literally subordinated to serve the felt needs of the people without compromising on the epidemiological efficacy of the program.

In light of the foregoing discussion on the epidemiology and social meaning of tuberculosis and the different views of the possible societal response, we can discuss the specific features of the health seeking behavior/felt needs of the tuberculosis patients, the scientific response and the response of the government with the 'able' advise and aid of the multilateral and bilateral agencies. The development and implementation of NTP and RNTCP serve as the most suitable tools to understand these. Besides these two specific programs, some other socio-economic considerations that are pertinent to the societal response to tuberculosis shall also be discussed.

\section{NATIONAL TUBERCULOSIS PROGRAM}

\section{Health seeking behaviour/Felt needs of the people}

In designing of NTP, learning from the people was the motto. Rather than the policy planners handing down a predestined technology as the solution, an effort was made to investigate what people did in response to TB and thereby develop a program to deliver a suitable technology.

We have already noted that almost all the cases of TB were aware of their symptoms and as many as half sought the help of the peripheral health institutions for the alleviation of their symptoms. These findings had some very crucial programmatic implications for tuberculosis control; which were the following: ${ }^{3}$

- There was a felt need for treatment of their symptoms among at least $50 \%$ of the patients and it was very likely that in these patients the symptoms were advanced enough to render them as infective cases and hence an epidemiological priority. There was thus an overlap between epidemiological need and felt need.

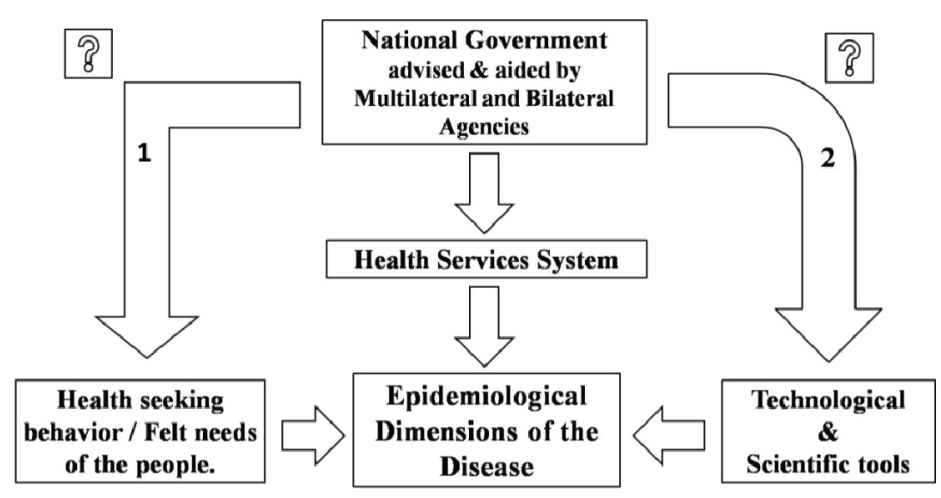

Paradigm 1 = Subordinating technology to felt needs of the people

Paradigm 2 = Subordinating people to the needs of delivering specified technology

Figure 1: The dilemma of the public health response to the epidemiological problem of a disease. 
- Given the present state of health services at that time the felt needs of the TB patients were not being fulfilled by the general health services.

- If the felt needs of the patients seeking treatment could be met effectively then it was possible that those who were worried of their symptoms could be motivated to seek treatment and encouraged by this behaviour of the patients and the responsiveness of the health services, the patients who were conscious of their symptoms could get worried or even seek treatment; meaning thereby that the program could achieve a wide coverage through setting this internal dynamics in motion, ${ }^{4}$ without there being the need of 'motivational manipulation' for 'patient catching' and 'patient holding'.

The health seeking behaviour of the people taught the scientists at the NTI that instead of formulating a vertical control program based on a structure of specialized TB clinics and tuberculosis hospitals the need was to fully integrate the program with the general health services; which is where the people went for alleviation of their suffering and simultaneously to strengthen these facilities to meet the felt needs. Further, the data available with NTI justified such an approach to be much more cost effective than any mass campaign. ${ }^{5}$ We have already noted that the incidence of tuberculosis had been declining in the world even before specific public health measures had been taken and that such a possibility could not be ruled out for India as well. ${ }^{6}$ Given these facts, a vertical mass campaign could have been nothing but sheer profligacy.

As opposed to the experience of vertical technology driven mass campaigns for control and eradication of malaria and the family planning program, which came at considerable cost to the development of the general health services, the wedding of NTP with the general health services meant that resources were spent on it only in proportion to which TB contributed to the overall suffering caused by disease and ill health. In fact demands had been made by the scientists associated with NTP, that the scope of the program should be expanded to provide for the care of chest symptomatic patients of other diseases of the lung and that the mandate of the different national and regional tuberculosis institutes in the country should be expanded to include treatment and research in other lung diseases. ${ }^{7}$

The sensitivity accorded to privileging people over the dominant techno-centric mindset of the times can be gauged from the fact that the sociologists at NTI rejected the conventional definition of a defaulter as one who did not take the full prescribed course of treatment. ${ }^{8}$ Instead of such a "techno-centric, arbitrary and value-loaded" definition they proposed that a defaulter be considered as one "whose actions cause suffering to him/her or other members of the community over a time span."

We have already seen in the section on epidemiology of tuberculosis that there is a considerable variation in the case types of tuberculosis, with as many as a third of even sputum positive cases remitting spontaneously. Further, many studies have shown high cure rates even among the defaulters which indicates a possibility that perhaps the patient's decision to discontinue treatment upon relief of his suffering was right and that the policy of having longer courses of treatment by all cases of tuberculosis needs revision. There apparently is considerable need to do further research for identifying different types of $\mathrm{TB}$ cases requiring treatment for short, intermediate or longer terms. ${ }^{7}$

\section{Response of the scientific community}

Firmly entrenching the NTP around the felt needs of the patients in the remotest corners presented a challenging task of subordinating technology to their needs. The foremost challenge here was of finding a way to diagnose tuberculosis cases in the remotest of areas using a technology that was 'Accessible, Available, Affordable and Acceptable.' These four 'A's that were to become the hallmark of the concept of 'primary health care' developed later, signified the subordination of technology to the needs of the people. Indeed, Halfdan Mahler, who was later to become the longest serving Director General of WHO and was the head of the international experts from WHO at the NTI involved in the formulation of NTP, himself declared at the silver jubilee celebrations of NTI that many of the principles developed in the course of formation of NTI directly fed into the Alma Ata declaration of $1978 .{ }^{9}$

Overdiagnosis of TB on x-ray diagnosis is a well recognized phenomenon. ${ }^{10}$ As chronic cough was the overwhelmingly dominant symptom present in the general population and almost all the TB cases were conscious of this symptom, it was deemed possible to diagnose TB cases by examining the sputum of the chronic cough cases visiting the general health services. Sputum microscopy was a technique that could easily be performed by peripheral health workers even in the remotest areas. Indeed the report of the 'In Depth Study on National Tuberculosis Program of India' by the ICORCI (Institute of Communication, Operations Research and Community Involvement) remarked - "that the general apprehension that microscopy of good quality is not possible in PHIs is without any foundation and should not come in the way of extending this service to as many PHIs as possible."11

In order to appreciate the significance of 'sputum microscopy' as an extraordinary achievement, one has to understand the general atmosphere obtaining in the milieu 
of the late fifties and early 60 s when $\mathrm{x}$ - ray radiography was among the most sophisticated technology. In those days "X Ray and BCG were kings" and "the horrible limitations of X Ray were kept hidden by the X ray industry" with full backing of "the top experts." 12 The enduring scientific validity of sputum microscopy is attested to by the fact that it remains the primary method of diagnosis even in RNTCP.

NTP used treatment regimens that constituted cheaper, easily available drugs which could have a much wider coverage. Rifampicin which was introduced in 1967 was reserved for more difficult cases.

The response of the scientific community came in the form of many other landmark studies which fed into the formulation of NTP. The National Sample Survey for tuberculosis, 1955-58, conducted by the Indian Council of Medical Research (ICMR) provided the epidemiological dimensions of the public health problem of tuberculosis in India ${ }^{13}$ and facilitated more detailed epidemiological studies which helped define a case of tuberculosis. ${ }^{14,15}$ A study into the protective efficacy of BCG vaccine showed it had no protective effect in adults and led to the abandonment of BCG vaccination in adults across the world. ${ }^{3}$

Field epidemiological studies carried out the New Delhi Tuberculosis Centre and the Tuberculosis Chemotherapy Centre, Madras (rechristened as Tuberculosis Research Centre) conclusively demonstrated that the domiciliary treatment was as good as the sanatorium treatment. It also provided the organizational structure of domiciliary treatment and helped clear many of the social taboos associated with the disease. ${ }^{3,16}$

Operations research methodology was adopted in formulating the organizational structure of the program delivery, institutional support for training of personnel, monitoring and supervision etc and to come up with the best possible solution under the given conditions of epidemiology of the disease and limited resources. ${ }^{3}$

NTP presented an ideal example of interdisciplinary research in health program formulation with experts from fields like epidemiology, biostatistics, phthisiology, bacteriology, public health nursing and sociology being involved as equal members of the team. ${ }^{3}$ Unlike the experience of most of the other health programs NTP presented the most positive picture of international cooperation in health sphere where in a team of scientists from WHO worked with their Indian counterparts as equals rather than in the manner of tutoring, as is usually the case. ${ }^{3}$ Importantly, they were willing to learn from their Indian counterparts. These achievements of NTP are attested to by the fact that NTP "won recognition from many foreign countries as a highly rational and applicable programme" and that NTI trained "trained over 1,000 TB workers from India and some other countries" in the first 6 years of its existence. ${ }^{17}$ That the public health concepts developed during the formulation of NTP should have directly fed into the making of the most important idea of international health in the $20^{\text {th }}$ century - 'Primary Health Care', is a fact that the country can justifiably be proud of.

\section{Response of the government and international agencies}

To be fair to the political leadership and the government health machinery of the time at Centre and the concerned States, none of the above achievements of NTP could have been possible without their political, administrative and logistical support. NTI had received from the government "the political mandate to design a nationally applicable, socially acceptable and epidemiologically effective tuberculosis programme for India." ${ }^{18}$ Besides this the governments at the Centre and the States did establish an elaborate network of 'State TB Training and Demonstration Centers' and 'District Tuberculosis Centers (DTC)' in a relatively short period of time. A total of 446 districts had DTCs, while an additional $330 \mathrm{~TB}$ clinics were functioning in the major cities and towns of the country. These institutions served the function of training of medical and paramedical personnel, institutional, referral, technical and supervisory support to the peripheral health institutions. ${ }^{19}$

However, this initial support to NTP proved to be unsustainable during the subsequent course of the program as could have been expected due to the general neglect of the health services in India. NTP was designed to sink or sail with the general health services - a laudable public health objective in itself. Major responsibility for this neglect lies with the political leadership in the country which never prioritized the health needs of the people as compared to expenditure on say defense, or allowing huge sums of public money to be siphoned off in so many scams which by now have become only an expected norm in India. Secondly, the generalist bureaucracy in the health set-up that has neither the understanding of the principles underlying public health programs, nor is accountable to anyone for their actions due to possible transfers from one ministry to another, ${ }^{20}$ also contributed to lop sided health planning.

The government itself constituted an in depth study of the NTP from an independent body - ICORCI (Institute for Communications, Operations Research and Community Participation). ICORCI submitted its report in 1988 with 86 detailed recommendations for improving the functioning of the NTP in the country. It said categorically that - "It has been repeatedly brought to the attention of the Expert 
Team that NTP has been given a low priority. This has also been confirmed by the analysis of information collected." 21 The government did not act on even one of these recommendations.

Such profound nihilism on part of the government led to the degeneration of Institutes of such national importance as the NTI. Not resting on its laurels, when in 1970 NTI sought permission from the government to conduct operations research into improving the functioning of the general health services and to evolve NTP implementation for taking care of the $90 \%$ of the chest symptomatic who were not tuberculous and were being left uncared for by the program; "pat came the snub that NTI should confine its activities to the field of tuberculosis only", ${ }^{7}$ notwithstanding the fact that if chest symptomatic patients were not cared for it would directly affect case detection in NTP which relied on the felt need of the symptomatic patients who came seeking relief from their suffering to the general health services.

The progressive decline in the number of research projects taken up and completed and published papers from NTI (table 1) over the years of the implementation of NTP speaks the story better than words. ${ }^{21}$ The research publications seem to have picked up only with the coming of World Bank funding associated with RNTCP. ${ }^{22}$ As a matter of fact the ICORCI report notes that "the absence of more recent studies which provide back-up for training has resulted in embarrassing situations for NTI during training courses and seminars." ${ }^{23}$

The situation so created left the NTP like an orphan child of uncaring parents, leaving the space wide open for the Western agencies and their experts to dictate the new counters of the TB program. The 1992 review of NTP conducted by the Government of India with the able guidance of SIDA and WHO adopted a victim blaming approach towards $\mathrm{NTI}^{24}$ and ended up throwing the baby out with the bath water. The fact that despite the all round neglect of the program there had been cure rates of $83 \%,{ }^{25}$ $90 \%{ }^{26}$ and $96 \% 0^{27}$ in those who completed treatment satisfactorily without any supervision and consistently above $70 \%$ even in the defaulters; ${ }^{28,29,30,31,32}$ were conveniently ignored; as was also ignored the fact that despite such a poor performance of NTP there had been no proportionately rapid increase in the incidence and prevalence of tuberculosis in the country. ${ }^{33,34}$

There was restlessness among the health planners in the country to implement a TB program with a renewed vigor, not because the TB patients in this country had been allowed to suffer for too long, but because TB resurfaced where it was least expected; in the industrialized West and the poor of the developing countries became a potential source of the more dreaded forms of the disease.

\section{REVISED NATIONAL TUBERCULOSIS CONTROL PROGRAM (RNTCP)}

The RNTCP was first implemented in India in 1993 in the form of a pilot project and was gradually extended throughout the country in different phases. It is claimed that the entire country was covered by RNTCP as on March 2006.

Before we progress further, the meaning of the mandate given to NTI i.e. to devise a program that is 'nationally applicable', 'socially acceptable' and 'epidemiologically effective' is worth emphasizing here. For a country of the size of India the meaning of these terms derives from the fact that there is considerable variation in the epidemiological factors, in cultural acceptability of a given health intervention and hence its uniform applicability in the different parts of the country. The same also holds true for the different countries of the world.

\begin{tabular}{|c|c|c|c|c|c|}
\hline \multirow{2}{*}{ Period } & \multicolumn{2}{|c|}{ Number of studies } & \multicolumn{2}{|c|}{ No of papers from studies } & \multirow{2}{*}{ Total no of papers } \\
\hline & Initiated & Completed & Published & For internal use & \\
\hline $1960-64$ & 66 & 58 & 30 & 24 & 48 \\
\hline $1965-69$ & 32 & 25 & 16 & 6 & 55 \\
\hline $1970-74$ & 19 & 15 & 13 & - & 58 \\
\hline $1975-79$ & 23 & 10 & 4 & 1 & 81 \\
\hline $1980-84$ & 15 & 14 & 13 & - & 50 \\
\hline $1985-88$ & 17 & 2 & 1 & 0 & 18 \\
\hline Total & 172 & 124 & 77 & 31 & 310 \\
\hline 1989-93 & - & - & - & - & 55 \\
\hline $1994-98$ & - & - & - & - & 39 \\
\hline 1999 & - & - & - & - & 8 \\
\hline
\end{tabular}

Source: ICORCI report on NTP for figures upto 1988 and NTI website for figures from 1989 to 1999. 
A necessary condition imposed by these circumstances is that in order to be successful a health program has to be context specific such that it has maximum epidemiological impact on the morbidity and mortality due to disease. There can be no one size fits all strategy. However, such a program can come about only if it is human suffering that is at the core of the planning process.

We have already seen that resurgence of tuberculosis in the New York City created considerable panic there. At its peak there were 3,800 cases in the city in 1992. The authorities responded by expanding the directly observed therapy. The response to take care of 3,800 patients cost more than dollar 1 billion, with immeasurable human cost. ${ }^{35}$ Even though it was a home grown epidemic due to totally indigenous societal conditions, the repercussions of it were to be global as the poverty stricken billions in the developing countries became the prime suspects as the source of TB, especially multidrug resistant type in conjunction with HIV/AIDS.

The resurgence in West put TB firmly on the international health agenda. WHO declared TB a global emergency in 1993. A new joint global strategy was evolved by the WHO and IUATLD (international union against TB and lung diseases). The strategy was initially called 'Framework for Effective Tuberculosis Control ${ }^{36}$ and by 1995 it was branded as DOTS. Researchers have conclusively shown that DOTS was massive 'branding' and 'marketing' exercise undertaken by WHO, World Bank and other multilateral and bilateral agencies at the behest of the industrialized nations of the West. So much then, for the epidemiological and cultural specificity of DOTS.

These opening remarks about RNTCP are to bring home the point that rather than build upon the experience obtained over the years from the implementation of NTP by undertaking fresh research to plug in the gaps that had been identified, and make treatment more specific to the requirements of individual patients, our policy planners chose to implement a totally foreign inspired program. Indian tuberculosis workers were forced into the role of being foster parents to a TB control program with which they identified little.

\section{Standing pillars of DOTS strategy}

The two standing pillars of DOTS strategy are: ${ }^{37}$

1. "Emphasis on the cure of infectious and seriously ill patients of tuberculosis, through administration of supervised short course chemotherapy, to achieve a cure rate of at least $85 \%$."

2. "Augmentation of case finding activities to detect $70 \%$ of estimated cases" among the chest symptomatic patients presenting themselves in the treatment facilities.
On face of it these are very laudable objectives built around the concept of felt needs of the people. The point however is, who is to fulfill these felt needs. As per the program, the above mentioned rates are meant for patients visiting public health care facilities. However, a considerable majority of TB patients continue to seek care from private health set-ups. ${ }^{38,39}$ In states with better performing public health services, nearly $50 \%$ of TB patients seek care from public health services. ${ }^{40}$ Hence, unless a mechanism can be built to feed in data regarding patients diagnosed and treated by private health care providers, even the achievement of these targets in public health care will give a feeling of false reassurance at best.

Neither TB patients nor does TB care stand in isolation from the general movement in the health care scenario in the country. As of date in India more than $80 \%$ of health care is in private sector, ${ }^{41}$ the position of public health care has been considerably weakened in general. As someone has remarked, it is "poor service for poor people". India's private health care is least regulated, which means it is very difficult to either monitor treatment or to assimilate data of TB patients treated in private sector.

To add to the woos, the structural adjustment reforms in health sector have widened inequities in access and geographical distribution of health care services. ${ }^{42}$ User charges have become universally applicable feature of health policy in India under the reforms. ${ }^{43}$ All these are features that work to the detriment of the poor who constitute a overwhelming majority of the TB patients. Besides TB they are more likely to have other co-morbidities. The aforementioned then become factors that have very important and grave implications for the successful implementation of RNTCP.

NTP propagated the concept of 'felt need' by strongly wedding it to the improvement of general health services. Compared to the 1960s, the public health services are a lot less privileged today; hence, whatever may be the lip service paid to the integration of RNTCP with the general health services, the overall condition is not conducive to enable the desired treatment for a poor TB patient. Under the conditions claims of having achieved $85 \%$ cure rate and $70 \%$ case detection rate become circumspect.

An added cause of worry is the target oriented approach of RNTCP. Targets imply that they are to be met and in such a high voltage program as RNTCP which has the World Bank, the WHO and the powerful nations of the West vying for it, there can be a considerable pressure on the health workers to meet these targets anyhow. The program itself becomes blind to investigating the possible programmatic reasons in case the targets are not achieved, for the ingrained conviction is that the "programme per se 
is infallible.' There are reports of patients not being taken on to treatment in the program for non-medical reasons. The exclusions have been as high as $58 \% .^{44}$ The joint programme review of 2003 also observed that a significant number of patients diagnosed at the government health facilities are not registered and offered RNTCP regimens; though unfortunately the exact figures were not mentioned. ${ }^{45}$ Such practices are downright unethical. Little wonder then that it has been remarked - "the structure of the programme does not allow inculcation of an ethics of caring" ${ }^{\text {" It }}$ is instructive to bear in mind that those denied treatment are likely to be the ones in need of treatment the most.

\section{Some issues regarding treatment of cases}

The treatment regimens under NTP had kept important and potent drug like Rifampicin reserved for relapse or resistant cases. ${ }^{47}$ Under RNTCP however, Rifampicin in combination with other drugs has been made the standard bearer of treatment. Besides increasing the cost of treatment in the initial period, this practice has taken away an important reserve for treating relapse and resistant cases. Unfortunately when the system itself promotes liberal use of drugs in this manner without discretion, the private practitioners are only bound to go two steps ahead. The indiscriminate use of second line drugs in private is very well known. Since the second line therapy is still very costly, the use of Rifampicin as first line drug means that, once resistance develops to it, the poor patients with resistant infection shall have no recourse left in private care.

By prescribing one standard regimen for a standard time period to all patients of a category (there are three categories of patients under RNTCP, category I, II and III depending upon whether it is a new case, or a relapse or multi drug resistant case) RNTCP indulges in considerable overtreatment of patients by being oblivious to the differences in the requirements of different patients. This result not only in considerable waste of resources, but also side-effects of treatment to the patient and may not portend well for treatment compliance on a longer term basis.

\section{Treatment outcomes}

Table 2 below presents the success, death, failure and default rates among the new smear positive cases over the years. ${ }^{48}$

It appears from table 2 that RNTCP has been a fairly successful program from the very early stages of its implementation in the country which seems rather incredible given the dilapidated condition of public health care, especially in the rural areas. National Rural Health Mission came about only in 2005, and in this too the focus has almost exclusively been on 'institutional deliveries'. RNTCP has created a peculiar category of 'success rate', even though the 'cure rates' and 'failure rates' have been time tested monitoring criterion for

\begin{tabular}{|c|c|c|c|c|}
\hline \multirow{2}{*}{ Year } & \multicolumn{4}{|c|}{ New smear-positive } \\
\hline & Success & Death & Failure & Default \\
\hline 1999 & $82 \%$ & $5 \%$ & $3 \%$ & $9 \%$ \\
\hline 2000 & $84 \%$ & $4 \%$ & $3 \%$ & $8 \%$ \\
\hline 2001 & $85 \%$ & $5 \%$ & $3 \%$ & $7 \%$ \\
\hline 2002 & $87 \%$ & $4 \%$ & $3 \%$ & $6 \%$ \\
\hline 2003 & $86 \%$ & $5 \%$ & $2 \%$ & $6 \%$ \\
\hline 2004 & $86 \%$ & $4 \%$ & $2 \%$ & $7 \%$ \\
\hline 2005 & $86 \%$ & $5 \%$ & $2 \%$ & $7 \%$ \\
\hline 2006 & $86 \%$ & $5 \%$ & $2 \%$ & $6 \%$ \\
\hline 2007 & $87 \%$ & $5 \%$ & $2 \%$ & $6 \%$ \\
\hline 2008 & $87 \%$ & $4 \%$ & $2 \%$ & $6 \%$ \\
\hline
\end{tabular}

Source: RNTCP status report 2010, TBC India.

TB. Whatever may be its other advantage, the term 'success rate' (cure rate + successful completion of treatment) does help in creating an illusion of better performance. ${ }^{7}$ If the programme is indeed being implemented so successfully then the 'success rates' should have risen further; it is somewhat strange that the success rate have platued rather close to the program target of $85 \%$ success rate..

Performance of RNTCP between $4^{\text {th }}$ quarter 2008 and $3^{\text {rd }}$ quarter 2009 shows that none of the states or union territories, with the exception of Lakshadweep (100\%), Mizoram (91\%) and Nagaland (90\%) (which are too tiny to make any impact in the overall figures), have achieved cure rates exceeding $87 \%$. In comparison to this we have seen earlier that under NTP without any supervision some of the series reported cure rates in the range of $72 \%$ to $96 \%$, despite the program's low priority and without there being any unethical exclusion of patients. ${ }^{7}$

Routine figures generated through the program are actually not a very reliable indicator of its performance. These need to be confirmed by conducting special studies to collect longitudinal data on cure or relapse among different categories of patients. Such studies in the case of RNTCP are few and far between. In the first such study for RNTCP a cohort of 271 patients in Bangalore city were followed for two and a half years. The success rate recorded was $67.9 \%$ and as many as $24.7 \%$ defaulted. Treatment failure and deaths were $5.2 \%$ and $2.2 \%$ respectively. ${ }^{49}$ This certainly does not establish the superiority of DOTS over the Short Course Regimens of NTP.

\section{Agenda for research under RNTCP}

The purpose and the meaning of research is that it should have a wide vision before it as opposed to tubular one and should be guided by the epidemiological dimensions of the public health problem. For research to be fruitful the results should be placed for full public scrutiny and debate. Deriving from the results of the debate the policy makers 
should be prepared to revise the present policy. But this is impossible to do if the purpose of research is to validate given results and strategies. With surcharged battle cry being - 'DOTS is the answer', little research could have been entertained on topics that would make the very 'answer' questionable.

We have already outlined some of the most pertinent issues for research that were thrown up by NTP. These were issues fundamental to the very epidemiology of TB; but most unfortunately there is little attempt to address these issues under RNTCP for the program is blind to these.

\section{CONCLUSON}

The foregoing discussion should make this amply clear that our advocacy of NTP with the necessary inputs and research to improve its functioning is not a matter of obstinate sentimentalism. There are very sound scientific reasons for it rooted in the sociological understanding of the disease and the features of epidemiology that emanate from it. Indigenously developed programs that are based on the local social, epidemiological and political context lead the country on to the path of self reliant development contrary to the impact of the foreign inspired programs. Who could have had any objections if RNTCP were to be developed by removing the shortcomings of NTP through proper research into questions thrown up by the implementation of NTP?

Even more than fifteen years after having been launched in the country RNTCP remains crucially dependent on foreign aid. RNTCP status report 2010 shows that in every part of the country the program is being implemented with the help of loans or aid from the World Bank and the Global Fund for AIDS, Tuberculosis and Malaria and USAID. No aid or loan is without conditions which threaten the country's sovereignty.

We can also see from sections of this paper that a clear conceptualization of the social meaning of the disease and the dilemmas involved in deciding the path to be adopted in policy formulation is very crucial in determining the public health response to the disease. However, for a policy establishment dominated by generalist administrators and physicians seeped in the biomedical understanding of disease, these aspects are vague theoretical constructs at best. They do not entertain any dilemma; the clear direction is to act as the imperialist masters dictate.

These are aspects about which the public health personnel, the medical fraternity and the people at large need to be repeatedly made aware of for the weight of the public opinion to have a bearing on the political leadership and the 'obstinate' policy establishment.

\section{ACKNOWLEDGEMENT}

Authors would like to acknowledge the concepts taught in the 'Communicable Diseases' course taken by Prof. Ritu Priya at the Centre for Social Medicine and Community Health, Jawaharlal Nehru University. These concepts directly fed into the writing of this manuscript.

\section{REFERENCES}

1. Walsh J A and Warren K S. Selective primary health care: an interim strategy for disease control in developing countries. N. Engl. J. Med, 1979; 301:967-74.

2. Rllkin S B and Wall G, eds. Special issue: selective or comprehensive health care? (Whole issue.), Sot: Sci. Med., 1988; 26 (9):101 p.

3. Banerji D. A Social Science Approach To Strengthening India's National Tuberculosis Programme, Ind. J. Tub. 1993, 40: p 61-82.

4. Banerji, D. and Andersen, S. A Sociological Study of the Awareness of Symptoms Suggestive of Pul- monary Tuberculosis, Bulletin of World Health Or- ganization, 1963, 29 (5), 665.

5. Sikand, B.K. and Raj Narain. Known and Un- known Cases of Pulmonary Tuberculosis in a Population, Indian Journal of Tuberculosis, 1957, 5 (3).

6. Gothi, G.D. Five year incidence of Tuberculosis and crude Mortality in relation to non-specific tuberculosis sensitivity. Indian Journal of Tuberculosis, 1976; 23:58.

7. Nair, S.S. (Retd Director (Evaluation), Ministry of Health and Family Welfare, Government of India.) Some important facts that need attention for success of RNTCP. Not intended for publication, Bangalore, India, 2006. Available from http://openmed.nic.in/1352/, on $19^{\text {th }}$ Oct 2010.

8. Banerji D. Effect of Treatment Default on Result of Treatment in a Routine Practice in India, Proceedings of the XXth International Tuberculosis Conference, Paris, International Union Against Tuberculosis, 1970.

9. Mahler, H. Address in National Tuberculosis Institute, Proceedings of Silver Jubilee Celebrations, N.T.I. Bangalore, 1985, 82.

10. Raj Narain, S. S. Nair, K. Naganna et. al. Problems in Defining a "Case" of Pulmonary Tuberculosis in Prevalence Surveys. Bull. Wid Hith Org., 1968; 39:701-729.

11. In Depth Study on National Tuberculosis Programme of India. Institute of Communication, Operations Research and Community Involvement, Koramangala, Bangalore, November 1988, p 114-115.

12. Personal communication from $\operatorname{Dr} D$ Banerji, one of the pioneers of the NTP and the Chief Sociologist at NTI at that time, Personal communication received through electronic mail on $14^{\text {th }}$ October 2010.

13. Indian Council of Medical Research. Tuberculosis in India: A Sample Survey, 1955-58. Indian Council of Medical Research, New Delhi.

14. Raj Narain, Geser A., Jambunath M. V. and Subramanian M. Some aspects of a Tuberculosis Prevalence Survey in a south Indian District, Bulletin of W.H.O. 1963; 29:641.

15. Raj Narain. Some aspects of the interpretation of the tuberculin test. Journal of Indian Medical Association, 1968; 50 (10). pp. 449-456.

16. Nagpaul D R: Role of the National Tuberculosis Institute (NTI) in Fight Against Tuberculosis. Souvenir of $2^{\text {nd }}$ Mysore State TB and Chest Diseases Workers' Conference, 1967, Mangalore, 107.

17. Nagpaul D R: Role of the National Tuberculosis Institute (NTI) in Fight Against Tuberculosis. Souvenir of $2^{\text {nd }}$ Mysore State TB and Chest Diseases Workers' Conference, 1967, Mangalore, 107.

18. National Tuberculosis Institute. Proceedings of Silver Jubilee Celebrations, NTI Bangalore, 1985.

19. Revised National Tuberculosis Control Program (RNTCP): DOTS Strategy including DOTS plus. In National Health Programs of India: National 
Policies and Legislations Related to Health by Jugal Kishore, $7^{\text {th }}$ Edition, Century Publications, New Delhi, 2007, p 173.

20. D Banerji. Serious Implications of the Proposed Revised National Tuberculosis Control Programme for India, Published by Voluntary Health Association of India and Nucleus for Health Policies and Programmes, New Delhi, 1997.

21. In Depth Study on National Tuberculosis Programme of India. Institute of Communication, Operations Research and Community Involvement, Koramangala, Bangalore, November 1988.

22. Bibliography of NTI Papers. Available from http://ntiindia.kar.nic.in/ ntipapers.htm on 21st October 2010.

23. In Depth Study on National Tuberculosis Programme of India. Institute of Communication, Operations Research and Community Involvement, Koramangala, Bangalore, November 1988, p 154.

24. Giri S. A study of the tuberculosis program in Nepal. A systematic perspective $\mathrm{PhD}$ thesis, Centre for Social Medicine and Community Health, Jawaharlal Nehru University, New Delhi, 2006.

25. Baily GVJ and Gothi GD: Proceedings of the $9^{\text {th }}$ Eastern Region Tuberculosis Conference and $29^{\text {th }}$ National Conference on Tuberculosis and chest Diseases, 1974; 367.

26. Jagota P, Gupta EVV, Nagaraja Rao BS, Parimala N and Baily GVJ. The Acceptability and Efficacy of two Regimens of Short Course Chemotherapy under conditions of an urban tuberculosis programme, Ind. J. Tub., 1989; 36: $p 18$.

27. Suryanarayana L, Vembu K,Satyanarayana C and Rajalakshmi R (1994): Status of Short Course Chemotherapy under National Tuberculosis Programme, Ind. J. Tub., 1995; 41: p 211-221.

28. Gothi GD, Savic D, Baily GVJ, Rao KP, Nair SS and Samuel R. Collection and consumption of self-administered anti-tuberculosis drugs under programme conditions, Ind. J. Tub., 1971; 18(4): p 107.

29. Jagota P, Gupta EVV, Sreenivas TR, Parimala N and Chaudhuri K. Operational feasibility of unsupervised intermittent Short Course Chemotherapy regimens at the District Tuberculosis Centre, Ind. J. Tub., 1991; 38: p 55.

30. Jagota P, Venkataramana Gupta EV and Channabasavaiah R. Fate of Smear Positive Patients of Pulmonary Tuberculosis at an Urban District Tuberculosis Centre, Five years after Treatment, Ind. J.Tub., 1994;41:p 223.

31. Jagota P, Sreenivas TR and Parimala N (1996). Improving Treatment Compliance by Observing Differences in Treatment Irregularity, Ind.J. Tub., 1996; 43: $p 75$.

32. Sophia Vijay, Balasangameshwara VH and Srikantaramu N (1999): Treatment dynamics and profile of tuberculosis patients under the District Tuberculosis Programme (DTP) - A prospective cohort study, Ind. J. Tub., 1999; 46: p 239.

33. Grzybowski, S., Epidemiology of Tuberculosis with particular reference to India, Ind. J. Tub, 1995; 42:195.

34. Chakraborty, A.K., Tuberculosis Situation in India : Measuring it through Time Ind. J. Tub., 1993; 40:215.
35. Lessons from New York's tuberculosis epidemic;Tuberculosis is a political as much as a medical problem and so are the solutions, BMJ, 1998; Vol. 317 : p 616.

36. WHO. Framework for effective tuberculosis control, WHO/TB/94.179, Geneva, 1994.

37. Revised National Tuberculosis Control Program (RNTCP): DOTS Strategy Including DOTS Plus, In National Health Programs of India; National Policies and Legislations Related to Health, Kishore $\mathrm{J}$ (ed), $7^{\text {th }}$ edition, Century Publications, New Delhi, 2007.

38. Nagpaul DR, Chopra KK. Issues in tuberculosis control, Indian J Tuberc, 2002; 49:2.

39. Dholakia Y, Pawar V. Survey of diagnostic services in private health sector of Mumbai for assessment of TB case detection, Indian J Tuberc, 2006; 53:40-2.

40. Charles N, Thomas B, Watson B, Sakthivel M. R, V. C, et al. (2010) Care Seeking Behavior of Chest Symptomatics: A Community Based Study Done in South India after the Implementation of the RNTCP. PLoS ONE, 2010; 5(9): e12379. doi:10.1371/journal.pone.0012379.

41. Healthcarein India:Emergingmarketreport2007,PricewaterhouseCoopers. Available from http://www.pwc.com/en_GX/gx/healthcare/pdf/emergingmarket-report-hc-in-india.pdf on 20th Oct 2010.

42. Rama Baru, Arnab Acharya, Sanghmitra Acharya et.al. Inequities in Access to Health Services in India: Caste, Class and Region, Economic and Political Weekly, 2010; Vol. 45 (39):49-58.

43. Bajpai $V$ and Saraya $A$. User charges as a feature of health policy in India: A perspective, NMJI, 2010; Vol. 23 (3):163-170.

44. Lala Ram Swarup Institute of Tuberculosis and Allied Diseases (LRS), (1998): Final Report of the Operations Research to assess needs and perspectives of TB patients and providers of tuberculosis care in Nehru Nagar and Moti Nagar chest clinic areas of Delhi;DFID Health and Population Office, Delhi, as quoted in Chakraborty, A.K. Expansion of the Tuberculosis Programme in India: The Policy Evolution Towards Decentralization and Integration, The Centre for Health Research And Development (CHRD)A Unit of The Maharashtra Association of Anthropological Sciences (MASS), Pune, 2003.

45. World Health Organization, Joint Tuberculosis Programme Review, India, 2003.

46. Ritu Priya and Kaushal K Singh (2003): Ethical Aspects of the Tuberculosis Programme, Health Administrator, 2003; 15 (1and2):156.

47. Prahlad Kumar. Journey of Tuberculosis Control Movement in India: National Tuberculosis Programme to Revised National Tuberculosis Control Programme, Indian J Tuberc, 2005; 52:63-71.

48. TB India 2010: RNTCP status report, Central TB Division, Ministry of Health and Family Welfare, Government of India, p 100.

49. Sophia Vijay, V. H. Balasangameswara, P. S. Jagannatha et.al. Treatment Outcome and Two and Half Years Follow-up Status of New Smear Positive Patients Treated Under RNTCP, Indian J Tuberc 2004; 51:199-208. 